\title{
Cyanidin-3-rutinoside acts as a natural inhibitor of intestinal lipid digestion and absorption
}

\author{
Thavaree Thilavech ${ }^{1,2}$ and Sirichai Adisakwattana ${ }^{*^{*}}$ (D)
}

\begin{abstract}
Background: Cyanidin-3-rutinoside (C3R), a naturally occurring anthocyanin, possesses anti-oxidant, antihyperglycemic, anti-glycation and cardioprotective properties. However, its mechanisms responsible for antihyperlipidemic activity have not been fully identified. The aim of the study was to investigate the lipid-lowering mechanisms of C3R through inhibition of lipid digestion and absorption in vitro.

Methods: The inhibitory activity of C3R against pancreatic lipase and cholesterol esterase was evaluated using enzymatic fluorometric and enzymatic colorimetric assays, respectively. An enzyme kinetic study using MichaelisMenten and the derived Lineweaver-Burk plot was performed to understand the possible types of inhibition. The formation of cholesterol micelles was determined using the cholesterol assay kit. The bile acid binding was measured using the colorimetric assay. The NBD cholesterol uptake in Caco-2 cells was determined using fluorometric assay. The mRNA expression of cholesterol transporter (Niemann-Pick C1-like 1) was determined by RT-PCR.
\end{abstract}

Results: The results showed that C3R was a mixed-type competitive inhibitor of pancreatic lipase with the $I_{50}$ value of 59.4 $\pm 1.41 \mu \mathrm{M}$. Furthermore, C3R (0.125-1 mM) inhibited pancreatic cholesterol esterase about 5-18\%. In addition, C3R inhibited the formation of cholesterol micelles and bound to primary and secondary bile acid. In Caco-2 cells, C3R $(12.5-100 \mu \mathrm{M})$ exhibited a significant reduction in cholesterol uptake in both free cholesterol (17-41\%) and mixed micelles (20-30\%). Finally, C3R (100 $\mu \mathrm{M})$ was able to suppress mRNA expression of NPC1L1 in Caco-2 cells after $24 \mathrm{~h}$ incubation.

Conclusions: The present findings suggest that C3R acts as a lipid-lowering agent through inhibition of lipid digestion and absorption.

Keywords: Cyanidin-3-rutinoside, Anthocyanin, Cholesterol, Hyperlipidemia, Pancreatic lipase, Niemann-pick C1-like 1

\section{Background}

Hyperlipidemia is a group of metabolic disorders characterized by hypercholesterol and/or hypertriglyceride in blood circulation. The prevalence of hyperlipidemia has dramatically increased worldwide due to a sedentary lifestyle and consumption of high fat diets $[1,2]$. Longterm hyperlipidemia is an important risk factor in contributing to the development of cardiovascular diseases (CVD). The risk of developing cardiovascular diseases in subjects with hyperlipidemia was twice as high as in

\footnotetext{
* Correspondence: sirichai.a@chula.ac.th

${ }^{1}$ Phytochemical and Functional Food Research Unit for Clinical Nutrition, Department of Nutrition and Dietetics, Faculty of Allied Health Sciences, Chulalongkorn University, Bangkok 10330, Thailand

Full list of author information is available at the end of the article
}

subjects with normal lipid levels [3]. Currently, the inhibition of dietary fat digestion and absorption from the small intestine is an attractive target for the management of hyperlipidemia $[4,5]$. For example, ezetimibe is a cholesterol absorption inhibitor that can be used as monotherapy or a combination therapy with a first-line drug such as a statin. Evidence has demonstrated that a combination of ezetimibe and a statin caused the lowering of low-density lipoprotein (LDL) cholesterol and improved cardiovascular outcomes in patients after acute coronary syndromes $[6,7]$. However, the number of patients with elevated liver enzyme levels showed a significant increase with ezetimibe-statin combination therapy [8]. Therefore, current studies attempt to search for 
effective phytochemical compounds from dietary fruits, vegetables and herbal medicines as lipid-lowering agents $[9,10]$.

Phytochemical compounds in fruits and vegetables have been targeted to promote beneficial health effects, especially the prevention of pathophysiological conditions such as dyslipidemia, diabetes, hypertension and cancer [11, 12]. Anthocyanins are one of the largest groups of natural pigments responsible for red, purple and blue colors in fruits and vegetables. They have been proven to possess favorable antioxidant, anti-inflammatory and anti-diabetic properties under both in vitro and in vivo study [13]. Interestingly, a meta-analysis revealed that supplementation of anthocyanins reduced serum lipid profiles in dyslipidemia patients [14]. Cyanidin-3-rutinoside (C3R), a naturally occurring anthocyanin, is widely distributed in a high number of dietary sources, such as blackberry, mulberry and black raspberry [15, 16]. This compound has demonstrated promising benefits for reduction of postprandial glucose through inhibition of pancreatic $\alpha$-amylase and intestinal $\alpha$-glucosidase $[17,18]$. Another study suggests C3R could inhibit the glucose uptake in Caco-2 cells [19]. In vitro data supported the underlying mechanism and indicated that C3R might modulate postprandial glycemia by inhibiting carbohydrate digestive enzymes and decreasing glucose transport in the small intestine. C3R also regulated glucose uptake and increased GLUT4 expression in 3T3-L1 adipocytes through activation of the PI3K/Akt pathways [20]. Our studies found that C3R inhibited monosaccharideand methylglyoxal-induced protein glycation in bovine serum albumin $[21,22]$. A previous study has shown the vascular relaxing activity of $\mathrm{C} 3 \mathrm{R}$ and its protection against methylglyoxal-induced vascular dysfunction in rats [23]. However, available data on C3R mostly focused on its antidiabetic and anti-glycation activity. Existing researches have never established the potential effectiveness of C3R in relation to lipid-lowering activity. Therefore, the objective of the study was to determine whether C3R could inhibit pancreatic lipase, cholesterol esterase, and the binding of bile acid as well as the reduction of cholesterol micellization. Since the blood cholesterol level is also influenced by absorption of cholesterol in the small intestine, the effect of C3R on cholesterol uptake in the enterocytes was also determined.

\section{Methods}

\section{Chemicals and reagents}

Porcine pancreatic lipase, 4-methylumbelliferyl oleate (4MUO), oleic acid, phosphatidylcholine, glycodeoxycholic acid, taurodeoxycholic acid, taurocholic acid, porcine cholesterol esterase, orlistat, and $p$-nitrophenylbutylrate ( $p$ NPB) were purchased from Sigma (St. Louis, MO, USA). Total bile acid colorimetric assay kit and cholesterol test kit were obtained from GenWay (San Diego, CA, USA) and HUMAN GmbH Co. (Wiesbaden, Germany), respectively. Cholestyramine resin was purchased from RUBIÓ (Barcelona, Spain). Ezetimibe was purchased from Merck, Sharp \& Dohme (Kenilworth, NJ, USA). 22-(N-(7-nitrobenz-2-oxa-1,3-diazol-4-yl)amino)-23,24bisnor-5-cholen-3-ol (NBD-cholesterol) and TRIzol reagent were obtained from Invitrogen (Eugene, OR, USA). Cyanidin-3-rutinoside chloride was synthesized from quercetin-3-rutinoside according to a previous study [24]. All other chemical reagents used in this study were analytical grade.

\section{Pancreatic lipase assay}

Pancreatic lipase activity was determined according to a previous study with minor modifications [25]. The various concentrations of C3R were incubated with pancreatic lipase solution $(50 \mathrm{U} / \mathrm{mL})$ and $100 \mu \mathrm{M} 4-\mathrm{MUO}$ in Tris buffer, pH $6.9(13 \mathrm{mM}$ tris- $\mathrm{HCl}, 150 \mathrm{mM} \mathrm{NaCl}$ and $1.3 \mathrm{mM} \mathrm{CaCl}_{2}$ ) at $37^{\circ} \mathrm{C}$. After $30 \mathrm{~min}$ of incubation, the reactions were terminated by adding $100 \mu \mathrm{L}$ of $0.1 \mathrm{M}$ citrate buffer, $\mathrm{pH}$ 4.2. The amount of released 4-MUO was measured by using a spectrofluorometer at excitation wavelength $320 \mathrm{~nm}$ and emission wavelength $450 \mathrm{~nm}$. Orlistat was used as a positive control for this study. The results were expressed as percentage of inhibition:

$$
\begin{aligned}
& \text { \%Pancreatic lipase inhibition } \\
& \quad=\left[\left(\left(\mathrm{F}_{\mathrm{C}}-\mathrm{F}_{\mathrm{CB}}\right)-\left(\mathrm{F}_{\mathrm{S}}-\mathrm{F}_{\mathrm{SB}}\right) /\left(\mathrm{F}_{\mathrm{C}}-\mathrm{F}_{\mathrm{CB}}\right)\right)\right] \times 100
\end{aligned}
$$

$\mathrm{F}_{\mathrm{C}}$ was fluorescence intensity of control and $\mathrm{F}_{\mathrm{CB}}$ was the fluorescence intensity of control blank. $F_{S}$ and $F_{S B}$ were the fluorescence intensity of $\mathrm{C} 3 \mathrm{R}$ or orlistat and sample blank, respectively.

\section{Enzyme kinetic for pancreatic lipase inhibitory activity}

To investigate the type of inhibition of pancreatic lipase activity, the enzymatic analysis was performed according to the above-mentioned reaction. Maintaining the quantity of pancreatic lipase at $50 \mathrm{U} / \mathrm{mL}, \mathrm{C} 3 \mathrm{R}(50-200 \mu \mathrm{M})$ was measured in various concentrations of 4-MUO $(6.25-100 \mu \mathrm{M})$. The type of inhibition was calculated on the basis of Lineweaver-Burk reciprocally plotted data.

\section{Pancreatic cholesterol esterase assay}

The pancreatic cholesterol esterase assay was slightly modified according to a previous method [25]. Briefly, various concentrations of C3R were incubated with a mixture containing $5.16 \mathrm{mM}$ taurocholic acid, $0.2 \mathrm{mM} p$ NPB in $0.1 \mathrm{M}$ sodium phosphate buffer, and $\mathrm{pH} 7.0$ containing $100 \mathrm{mM} \mathrm{NaCl}$. The reaction was initiated by adding porcine pancreatic cholesterol esterase $(1 \mu \mathrm{g} / \mathrm{mL})$ at $37^{\circ} \mathrm{C}$ for $5 \mathrm{~min}$. The absorbance was measured at 405 $\mathrm{nm}$ using a microplate reader. Gallic acid was used as a 
positive control for this study. The percentage of inhibition was calculated following the equation below:

$$
\% \text { Inhibition }=\frac{\text { Abs Control-Abs Sample }}{\text { Abs Control }} \times 100
$$

\section{Cholesterol micellization}

Artificial micelles were performed according to a previously published report [25]. The mixture (containing 2 $\mathrm{mM}$ cholesterol, $1 \mathrm{mM}$ oleic acid and $2.4 \mathrm{mM}$ phophatidlycholine) was dissolved in methanol and dried under nitrogen gas. Then the mixture was re-dissolved with $475 \mu \mathrm{L}$ of $15 \mathrm{mM}$ PBS containing $6.6 \mathrm{mM}$ taurocholate salt, $\mathrm{pH}$ 7.4. The emulsion was sonicated twice for 30 min and incubated overnight at $37^{\circ} \mathrm{C}$. The various concentrations of C3R $(25 \mu \mathrm{L})$ were added to the mixed micelle solution and incubated at $37^{\circ} \mathrm{C}$ for $2 \mathrm{~h}$. The mixture was then centrifuged at $12,000 \mathrm{rpm}$ for $20 \mathrm{~min}$. The supernatant was collected for the determination of cholesterol using the cholesterol test kit. The percentage of inhibition was calculated following the equation below:

$$
\text { \%Inhibition }=\frac{\text { Cholesterol level in control-Cholesterol level in sample }}{\text { Cholesterol level in control }} \times 100
$$

\section{Bile acid binding assay}

The bile acid binding assay was performed according to a previous study [25]. Glycodeoxycholic acid, taurodeoxycholic acid and taurocholic acid were used as bile acid in this experiment. Briefly, various concentrations of C3R were incubated with each bile acid $(2 \mathrm{mM})$ containing $0.1 \mathrm{M} \mathrm{PBS}, \mathrm{pH} 7$ at $37^{\circ} \mathrm{C}$. After $90 \mathrm{~min}$ incubation, the mixtures were filtered through a $0.2 \mu \mathrm{m}$ filter to separate the bound from the free bile acids. The bile acid concentration was measured using total bile acid colorimetric assay kit. The percentage of inhibition was calculated following the equation below:

$$
\% \text { Inhibition }=\frac{\text { Bile acid level in control-Bile acid level in sample }}{\text { Bile acid level in control }} \times 100
$$

\section{Cholesterol uptake in Caco-2 cells}

Caco-2 cells were obtained from the American Type Culture Collection (ATCC ${ }^{\circ}$-HTB-37 $7^{\mathrm{mm}}$ ). Cells were maintained in Dulbecco's Modified Eagle's Medium (DMEM) high glucose containing $10 \%$ fetal bovine serum, $1 \%$ penicillin/streptomycin, and $1 \%$ non-essential amino acids. Cells were cultured at $37^{\circ} \mathrm{C}$ in a humidified incubator with $5 \% \mathrm{CO}_{2}$ and seeded on a 24-well plate at a cell density of 25,000 cells/well for 7 days to allow them to differentiate. During this period, cells were fed with fresh medium every 2 days. After 7 days, cells were starved with serum-free DMEM low glucose containing
$1 \%$ penicillin/streptomycin and $1 \%$ non-essential amino acids for $24 \mathrm{~h}$. Then cells were washed twice with Hanks' balanced salt solution (HBSS, pH 7.4, $140 \mathrm{mM} \mathrm{NaCl}, 5$ $\mathrm{mM} \mathrm{KCl}, 1.2 \mathrm{mM} \mathrm{Na} \mathrm{HPO}_{4}, 2 \mathrm{mM} \mathrm{CaCl}, 1.2 \mathrm{mM}$ $\mathrm{MgSO}_{4}, 20 \mathrm{mM}$ HEPES, $0.2 \%$ bovine serum albumin) and incubated in HBSS at $37^{\circ} \mathrm{C}$ before the experiments. After $1 \mathrm{~h}$, cells were incubated at $37^{\circ} \mathrm{C}$ for $1 \mathrm{~h}$ with free cholesterol (containing $0.5 \mathrm{mM}$ taurocholate salt and $25 \mu \mathrm{M}$ NBD-cholesterol) or mixed micelles (containing $0.5 \mathrm{mM}$ taurocholate salt, $50 \mu \mathrm{M}$ oleic acid, $20 \mu \mathrm{M}$ phosphatidylcholine and $25 \mu \mathrm{M}$ NBD-cholesterol) [26] as donor vehicles supplemented with C3R $(12.5-100 \mu \mathrm{M})$. Ezetimibe $(100 \mu \mathrm{M})$ was used as a positive control for this study. Cells were washed 5 times with cold HBSS and the fluorescence was measured at the excitation wavelength of $485 \mathrm{~nm}$ and emission wavelength of 535 $\mathrm{nm}$. Cells were then disrupted in a lysis buffer $(10 \mathrm{mM}$ tris- $\mathrm{HCl} \mathrm{pH} 7.4,150 \mathrm{mM} \mathrm{NaCl}, 1 \%$ triton-x-100, $1 \mathrm{mM}$ EDTA and $0.1 \%$ SDS) and lysed by the freeze-thaw method for 2 cycles. The lysates were centrifuged at $12,000 \mathrm{rpm}$ at $4{ }^{\circ} \mathrm{C}$ for $10 \mathrm{~min}$ and the supernatants were collected for the determination of protein concentration using a BCA kit (Thermo Fisher Scientific, Waltham, MA, USA) with bovine serum albumin as standard. The total protein represented the total number of cells used for normalization. The results were expressed as the percentage of cholesterol uptake corresponding to the control values.

\section{Gene expression}

Caco-2 cells were seeded on a 6-well plate at a cell density of 100,000 cells/well for 7 days to allow them to differentiate. During this period, cells were fed with fresh medium every 2 days. After 7 days, cells were treated with $100 \mu \mathrm{M}$ $\mathrm{C} 3 \mathrm{R}$ in serum-free medium, and then incubated at $37^{\circ} \mathrm{C}$ for 2, 6 and $24 \mathrm{~h}$. After incubation, RNA was extracted from cells using TRIzol reagent and converted to cDNA by ImProm- $\mathrm{II}^{\mathrm{Im}}$ Reverse Transcription System from Promega Corporation (Madison, WI, USA) according to the manufacturer's direction. The specific primer sequences were obtained from previous studies as follows: NiemannPick C1-like 1 (NPC1L1, forward: 5'-TATGGTCGCC CGAAGCA-3' and reverse: 5' ${ }^{\prime}$-TGCGGTTGTTCTGG AAATACTG-3') [27] and glyceroldehyde-3-phosphate dehydrogenase (GAPDH, forward: 5'-CATGAGAAGT ATGACAACAGCCT-3' and reverse: $5^{\prime}$-AGTCCTTCCA CGATACCAAAGT-3') [19]. RT-PCR was carried out in the CFX Connect ${ }^{\text {tw }}$ Real-Time PCR Detection System (Bio-RAD Laboratories Inc., California, USA) using SsoFast ${ }^{\mathrm{m}}$ Evagreen Supermix SYRB green detection (Bio-RAD) according to the manufacturer's instruction. All samples were carried out in triplicate. The values were normalized using GAPDH as an endogenous internal 
standard. The results were expressed as the level of relative quantity to control.

\section{Statistical analysis}

Data are represented as means \pm standard error of mean (SEM) for each group. The $\mathrm{IC}_{50}, K i$ and $K i$ ' values were calculated by using Sigma Plot 11.0. The multiple comparisons were analyzed by one-way ANOVA using Duncan post hoc. The effect of C3R on NPC1L1 gene expression at each incubation time was determined by Student's ttest. These analyses were performed using SPSS Statistics 17.0 (SPSS Inc., Chicago, IL, USA). A $p$ value of less than 0.05 was taken as the criterion of significance.

\section{Results}

\section{Pancreatic lipase inhibition}

As shown in Fig. 1b, C3R strongly inhibited pancreatic lipase activity in a concentration-dependent manner $(p<0.05)$. The half-maximal inhibitory concentration $\left(\mathrm{IC}_{50}\right)$ value of $\mathrm{C} 3 \mathrm{R}$ against pancreatic lipase was $59.4 \pm$ $1.41 \mu \mathrm{M}$, which was a lower potency than orlistat $\left(\mathrm{IC}_{50}=\right.$ $31.7 \pm 2.72 \mathrm{nM}$ ) (Fig. 1a).

To further explore the inhibitory characteristics of C3R, a kinetic inhibition study was performed using LineweaverBurk double reciprocal plots. As shown in Fig. 1b, a Lineweaver-Burk plot of C3R produced straight lines with different intersections for three concentrations of substrate. The lines for C3R had a point of intersection in the third quadrant, indicating that C3R activity was a mixed type competitive. The dissociation constant for C3R binding to free enzyme, $K i$, was $39.0 \pm 5.14 \mu \mathrm{M}$, while the dissociation constant for C3R binding with enzyme-substrate complex, $K i$, was $20.8 \pm 9.92 \mu \mathrm{M}$.

\section{Cholesterol esterase inhibition}

As shown in Fig. 2, C3R significantly inhibited cholesterol esterase in a concentration-dependent manner. The percentage of the inhibition of C3R $(0.125-1 \mathrm{mM})$ was $5-31 \%$, whereas $1 \mathrm{mM}$ gallic acid inhibited cholesterol esterase about $39 \%$.

\section{Cholesterol micellization}

Fig. 3 shows the percentage inhibition of C3R on cholesterol micellization. C3R (0.125-1 mM) markedly reduced the solubility of cholesterol in artificially prepared micelles by $9-20 \%$, whereas gallic acid $(1 \mathrm{mM})$ inhibited the formation of cholesterol micelles by about $64 \%$.

\section{Bile acid binding}

The percentage of taurocholic acid, taurodeoxycholic acid and glycodeoxycholic acid binding capacity of C3R is shown in Table 1. According to the results, C3R bound to bile acids in a concentration-dependent manner. When comparing the equal concentration of C3R
( $3 \mathrm{mM})$, the percentage of bile acid binding increased in the order of taurodeoxycholic acid $(20 \%)<$ glycodeoxycholic acid $(23 \%)<$ taurocholic acid $(25 \%)$. However, C3R was less potent than cholestyramine at equal concentrations.

\section{Cholesterol uptake in Caco-2 cells}

The cholesterol absorption in Caco-2 cells was significantly suppressed by C3R in both forms of free cholesterol and mixed micelles (Fig. 4). The reduced cholesterol uptake was observed at the lowest concentration of C3R $(12.5 \mu \mathrm{M})$. In free cholesterol, C3R inhibited cholesterol absorption in a concentration-dependent manner. When comparing at the same concentration $(100 \mu \mathrm{M}), \mathrm{C} 3 \mathrm{R}$ also decreased cholesterol absorption (41\%) as well as ezetimibe (42\%). However, C3R demonstrated a slight effect on suppression of mixed micelle cholesterol absorption (30\%). It was found that ezetimibe had a higher potency than C3R on reduction of mixed micelle cholesterol uptake (42\%).

\section{NPC1L1 gene expression}

The effects of C3R on NPC1L1 gene expression are shown in Fig. 5. There are no significant differences of NPC1L1 gene expression between the control and C3R after 2 and $6 \mathrm{~h}$ incubation. However, C3R caused a 7fold suppression in NPC1L1 gene expression after $24 \mathrm{~h}$ incubation.

\section{Discussion}

Clinical evidence revealed that supplementation of anthocyanin reduced total cholesterol, triglyceride and the level of low-density lipoprotein cholesterol (LDL-C) and increased the level of high-density lipoprotein cholesterol (HDL-C) in patients with dyslipidemia [28, 29]. The previous study reported that consumption of purified mulberry anthocyanins containing cyanidin-3rutinoside (C3R) effectively decreased serum lipid levels in high-fat fed mice [30]. However, the specific mechanisms of action by which C3R decreases serum lipid level are still unknown. We present the first report on lipid-lowering mechanisms of C3R, including inhibition of lipid digestive enzymes and absorptive processes.

Inhibition of fat digestive enzymes results in delaying the process of hydrolyzing dietary fats. Pancreatic lipase is the primary digestive enzyme that converts triglyceride substrates to monoglycerides and free fatty acids, which may form micelles that serve as necessary intermediates for absorption into enterocytes [4]. The inhibition of pancreatic lipase activity is the most widely studied mechanism for the identification of potential anti-obesity agents [4]. The results from the pancreatic lipase inhibitory activity of C3R are in agreement with previous reports suggesting that pure anthocyanins, cyanidin-3-glucoside (C3G) and peonidin-3-glucoside, and anthocyanins extracted 
A

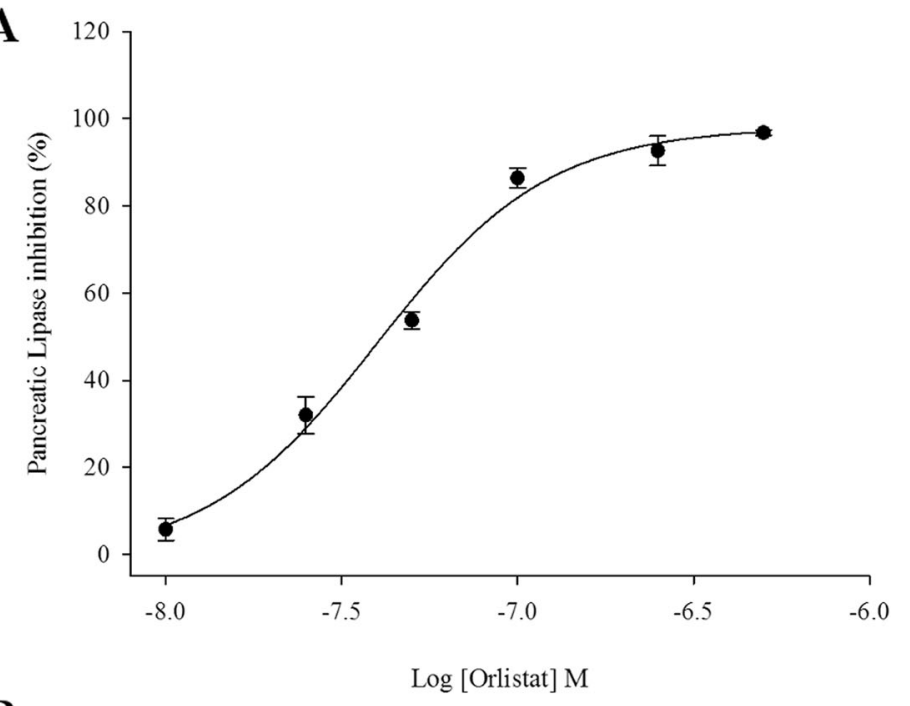

B

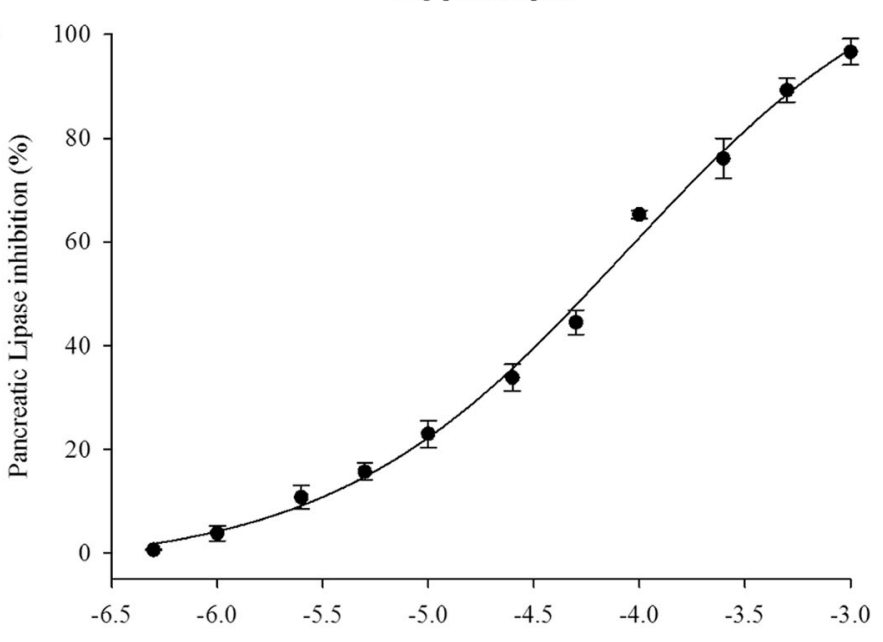

$\log [\mathrm{C} 3 \mathrm{R}] \mathrm{M}$

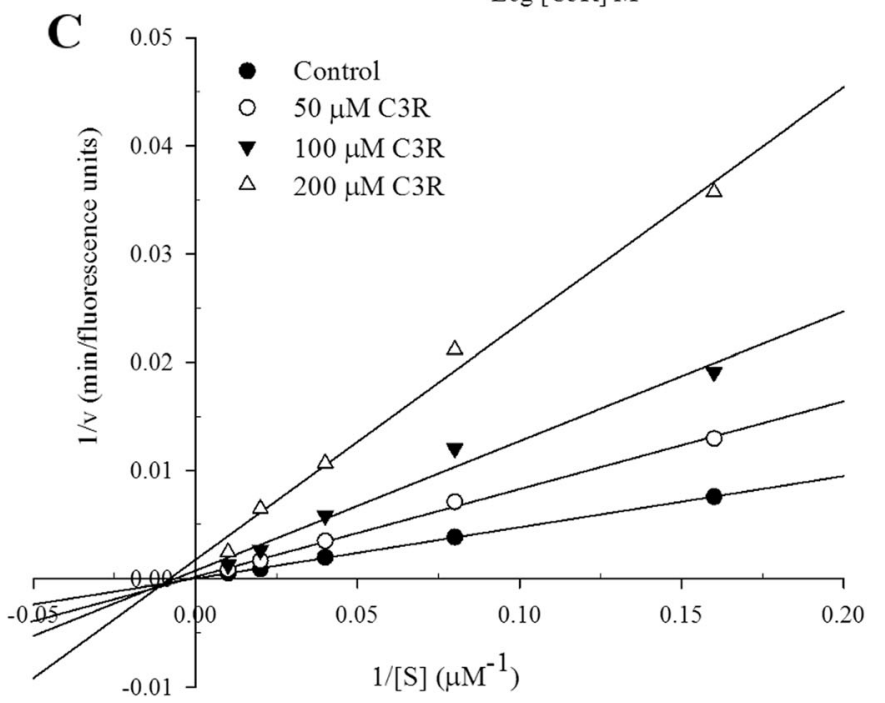

Fig. 1 The concentration-response curves of orlistat (a) and cyanidin-3-rutinoside (b). c Lineweaver-Burk plot of cyanidin-3-rutinoside for pancreatic lipase inhibition. The results are presented as mean $\pm \operatorname{SEM}(n=3)$ 


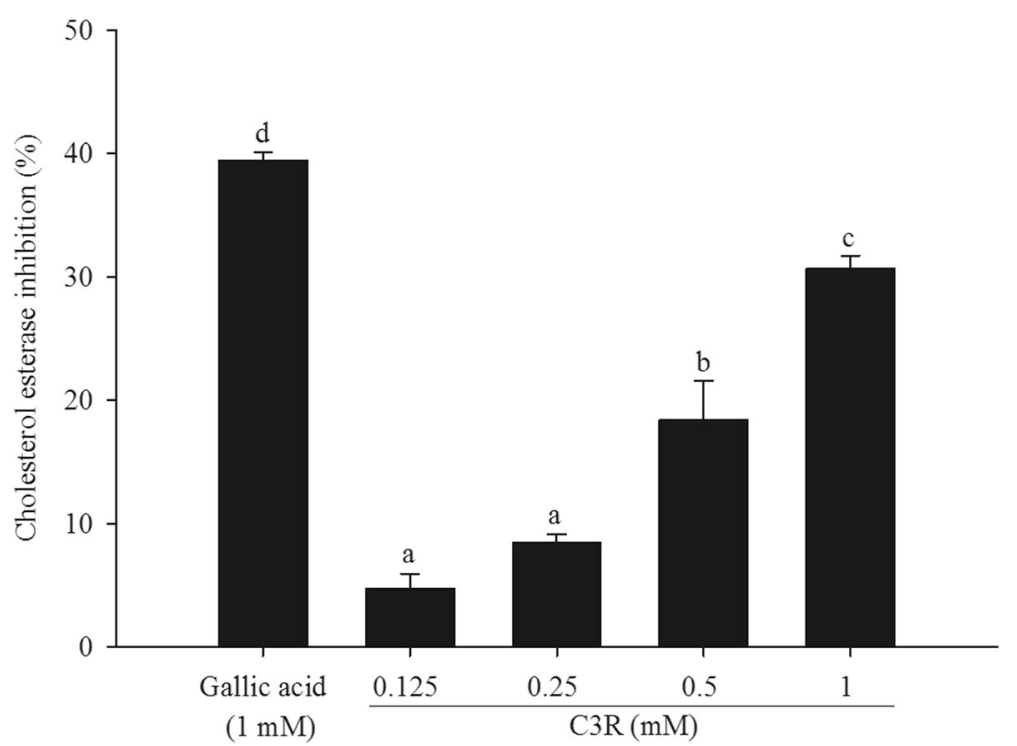

Fig. 2 The percentage enzyme inhibition of cyanidin-3-rutinoside (C3R) on cholesterol esterase. The results are presented as mean \pm SEM $(n=3)$. The groups that do not share a common letter are significantly different $(p<0.05)$

from dietary sources demonstrated inhibitory action against pancreatic lipase [31, 32]. Since understanding the mechanism of enzyme inhibition has become the basis of development of pharmaceutical agents, the study of the structure-enzyme activity relationship provides helpful information for drug design [33]. According to the results, C3R displayed a mixed-type competitive inhibitor against pancreatic lipase. The binding mode of C3R was assumed to be one inhibitor that can bind either to the active site of a free enzyme or to the enzyme-substrate complex.
When $K_{i}$ and $K_{i}^{\prime}$ dissociation constants were compared, it was found that the $K_{i}$ value of C3R was 1.9 times higher than the $K_{i}^{\prime}$ value, suggesting that binding of C3R to a free form of enzyme was stronger than the binding of C3R to enzyme-substrate complex. The results indicated that the pancreatic lipase inhibitory activity of C3R was noncompetitive predominant over competitive. However, the type of inhibition of C3R differs from earlier reports that cyanidin and its glycosides, including C3G and cyanidin-3, 5-diglycoside, were identified as a competitive inhibitor

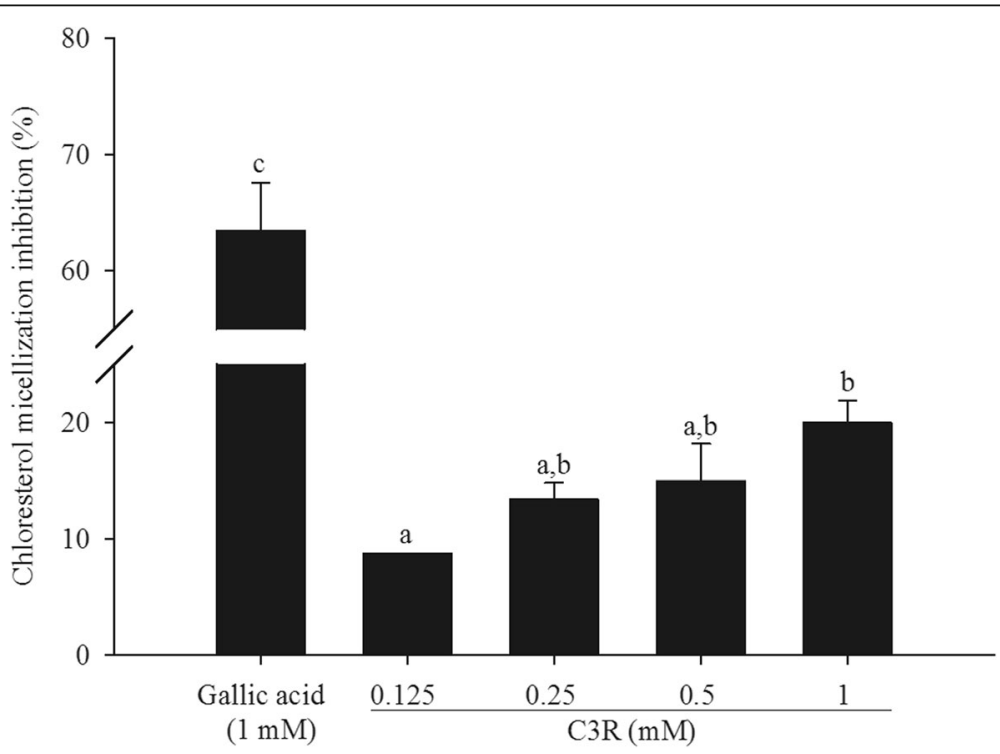

Fig. 3 The percentage inhibition of cyanidin-3-rutinoside (C3R) on cholesterol micellization. The results are presented as mean \pm SEM ( $n=3)$. The groups that do not share a common letter are significantly different $(p<0.05)$ 
Table 1 The percentage binding of cyanidin-3-rutinoside (C3R) on bile acids

\begin{tabular}{|c|c|c|c|c|c|c|c|c|c|}
\hline \multirow{3}{*}{$\begin{array}{l}\text { Experiments } \\
0.5 \mathrm{mM} \mathrm{C3R}\end{array}$} & \multicolumn{9}{|c|}{ Bile acid binding (\%) } \\
\hline & \multicolumn{3}{|c|}{ Taurocholic acid } & \multicolumn{3}{|c|}{ Taurodeoxycholic acid } & \multicolumn{3}{|c|}{ Glycodeoxycholic acid } \\
\hline & 15.1 & \pm & $0.6^{\mathrm{a}}$ & 13.0 & \pm & $0.3^{\mathrm{a}}$ & 11.7 & \pm & $1.7^{\mathrm{a}}$ \\
\hline $1 \mathrm{mM}$ C3R & 18.2 & \pm & $0.9^{\mathrm{a}}$ & 15.4 & \pm & $0.5^{\mathrm{ab}}$ & 15.3 & \pm & $0.1^{\mathrm{ab}}$ \\
\hline $2 \mathrm{mM} \mathrm{C} 3 \mathrm{R}$ & 22.8 & \pm & $0.5^{b}$ & 16.4 & \pm & $0.9^{b}$ & 19.2 & \pm & $0.4^{b c}$ \\
\hline $3 \mathrm{mM} \mathrm{C3R}$ & 24.8 & \pm & $0.9^{b}$ & 19.5 & \pm & $0.4^{c}$ & 22.7 & \pm & $0.3^{c}$ \\
\hline $3 \mathrm{mM}$ Cholestyramine & 37.1 & \pm & $0.1^{c}$ & 68.6 & \pm & $0.4^{d}$ & 60.2 & \pm & $1.0^{\mathrm{d}}$ \\
\hline
\end{tabular}

The results are expressed as mean $\pm \operatorname{SEM}(n=3)$. Groups without a common supercribed letter are significant difference $(p<0.05)$

$[31,34]$. It has been reported that cyanidin and C3G had three potential binding sites for porcine lipase-colipase complex within and near the active site, and cyanidin bound more effectively than C3G within (-9.8 vs. $-7.0 \mathrm{kcal} / \mathrm{mol})$ and near $(-8.8 \mathrm{vs} .-8.0 \mathrm{kcal} / \mathrm{mol})$ the active site [35]. Therefore, the different type of enzyme inhibition might be due to their glycosides at the 3-O-position of cyanidin, which may affect the binding site and binding affinity of the anthocyanins to the enzyme [36]. Therefore, further study is needed to evaluate the interaction between pancreatic lipase and C3R containing rutinose sugar at the 3-O-position using the molecular docking study.

Pancreatic cholesterol esterase plays an important role in the hydrolyzing of dietary cholesterol ester $(10-15 \%$ of total cholesterol in food) into non-esterified cholesterol which can be incorporated into mixed micelles and absorbed by enterocytes [37]. It has been reported that the inhibition of pancreatic cholesterol esterase caused a reduction in cholesterol absorption in hamsters fed a high cholesterol diet [38]. The current findings firstly revealed that C3R inhibited pancreatic cholesterol esterase activity, which is consistent with previous reports describing the potency of plant and fruit extracts against cholesterol esterase [25,39]. It has been stated that the structure of flavonoids is similar to that of cholesterol ester, which could irreversibly bind to the active site of the enzyme, resulting in inhibition of enzyme activity [40]. According to the basic structural feature of flavonoid compounds, C3R may act in the same manner.

Generally, the principle steps in absorption of dietary cholesterol are emulsification of dietary fat, micellization of cholesterol, and absorption of mixed micelles in the proximal jejunum [41]. One of the cholesterol-lowering mechanisms of flavonoids (tea catechins) is the interruption of cholesterol incorporation into micelles [42]. The present study indicated that micellization of cholesterol was inhibited by C3R. In support of this, the recent study revealed that cyanidin-3-glucoside (C3G) added to micellar solution precipitated with cholesterol and formed an insoluble complex [31]. Therefore, it could be hypothesized that C3R may prevent the formation of micelles due to having the same core chemical structure as C3G with a different type of sugar at the $\beta$-glycosidic linkage.

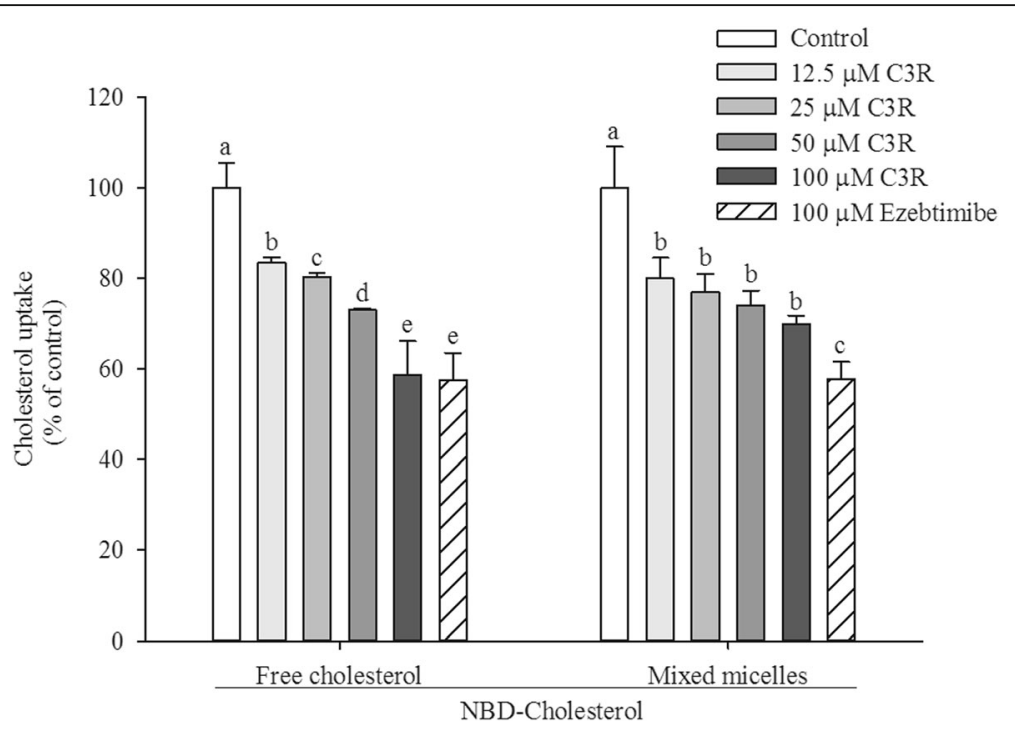

Fig. 4 The effect of cyanidin-3-rutinoside (C3R) on cholesterol uptake in Caco-2 cells in form of free cholesterol and mixed micelles. The results are presented as mean $\pm \operatorname{SEM}(n=3)$. The groups that do not share a common letter are significantly different $(p<0.05)$ 


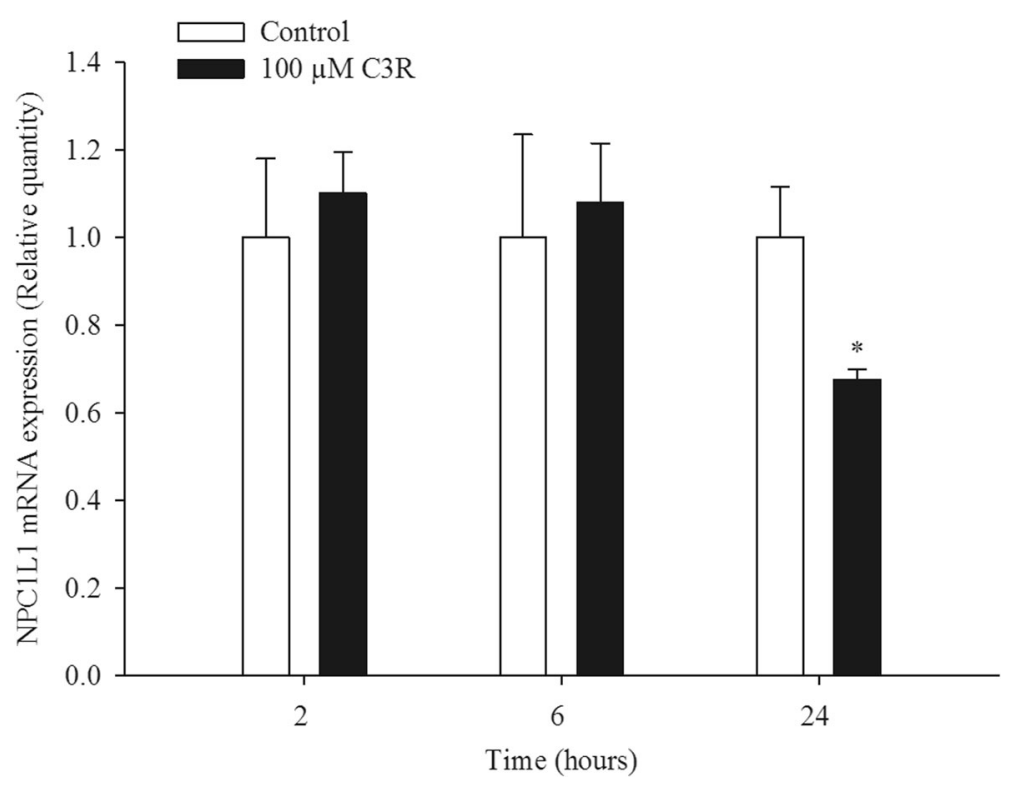

Fig. 5 The effect of cyanidin-3-rutinoside (C3R; $100 \mu \mathrm{M})$ on Niemann-Pick C1-Like 1 (NPC1L1) mRNA expression in Caco-2 cells after 2, 6, and 24 h incubation. The results are presented as mean $\pm \operatorname{SEM}(n=3)$. ${ }^{*} p<0.05$ compared to the control

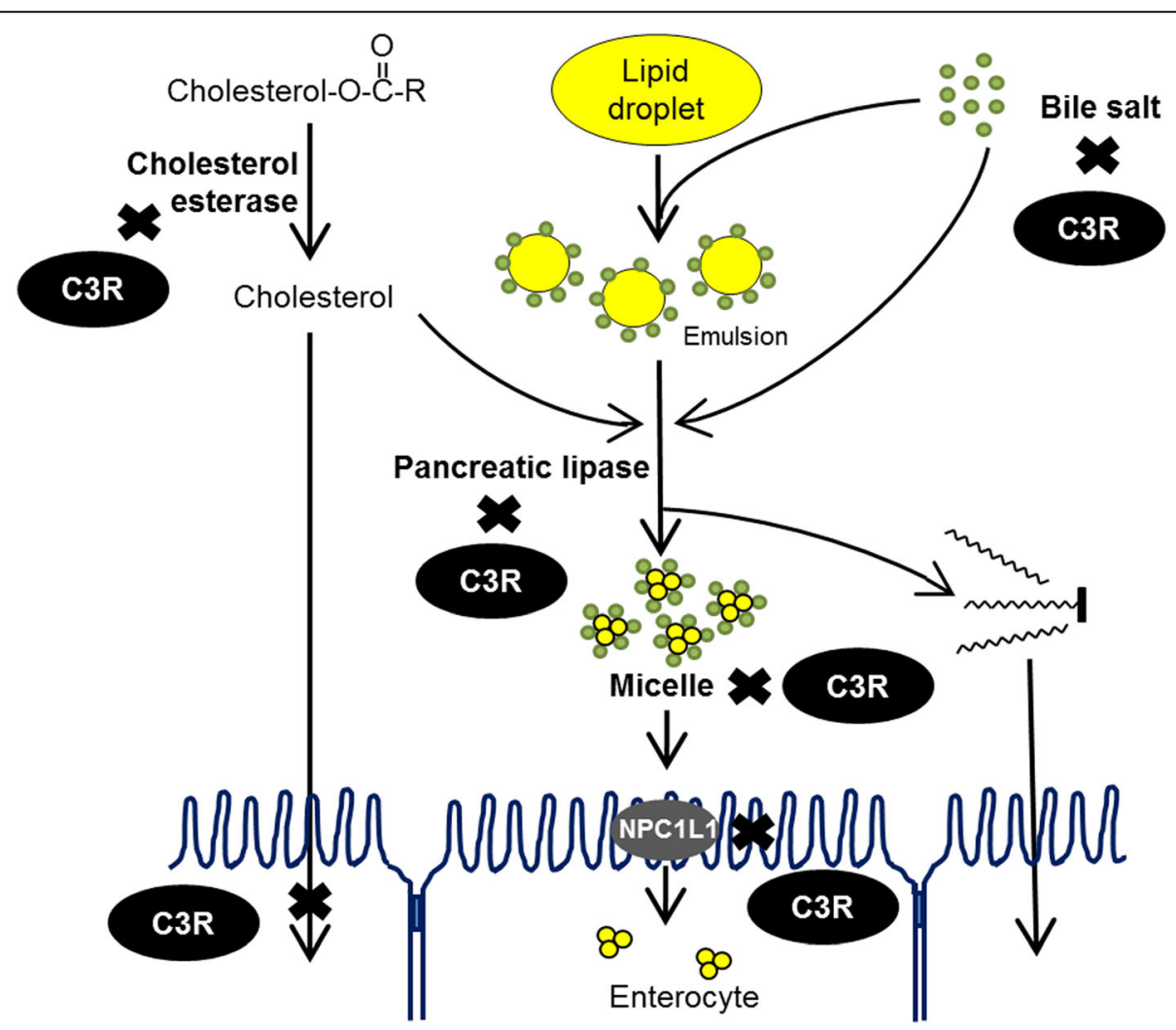

Fig. 6 A schematic illustrations of lipid-lowering actions of cyanidin-3-rutinoside (C3R) 
In addition to cholesterol, bile acids are also essential components in the formation of mixed micelles [41]. C3R exhibited the binding ability of bile acids, including taurocholic acid, taurodeoxycholic acid and glycodeoxycholic acid. C3R showed the strongest binding capacity to taurocholic acid, a primary bile acid directly synthetized by the liver, suggesting that C3R may disrupt the endogenous bile acid pool, causing the stimulation of bile acid synthesis from cholesterol and leading to the reduction of blood cholesterol [43]. Moreover, the binding of bile acids causes the formation of an insoluble complex and increases fecal bile excretion as well as disrupts the formation of micelles [43]. Taken together, these findings support the notion that C3R may act as the bile acid sequestrant, resulting in increased cholesterol metabolism and decreased cholesterol absorption into blood circulation.

Intestinal Caco-2 cells are a widely used human intestinal in vitro model that obtain results that usually correlate with human figures [44]. Since intestinal cholesterol absorption affects the levels of cholesterol in blood circulation, the effect of C3R on cholesterol uptake was determined in Caco-2 cells [44]. Our results demonstrated that C3R inhibited cholesterol uptake in both free cholesterol (containing only bile salt taurocholate) and mixed micelles (mimicking the mixed micelles found in dietary conditions). These results indicated that the action of C3R was independent of cholesterol micelle formation, and the reduction of cholesterol uptake was not due to a toxic effect of C3R on cell viability (data not shown). The results are consistent with previous reports that anthocyanins in black rice extract are a potent agent to reduce cholesterol uptake in enterocytes [31]. Interestingly, C3R showed sustained inhibitory effects similar to ezetimibe. This agent has a distinct mechanism as a selective cholesterol uptake inhibitor through binding of NPC1L1 at the brush border of the small intestine [45]. Our results found that anthocyanin C3R markedly decreased mRNA expression of NPC1L1 in Caco-2 cells. Nevertheless, the short-term mechanism by which C3R inhibits cholesterol uptake does not appear to relate to the suppression of NPC1L1 mRNA expression in Caco-2 cells. This conclusion is drawn from the fact that a significant decrease in NPC1L1 mRNA expression was observed only at $24 \mathrm{~h}$ incubation with C3R, whereas there was no significant alteration of NPC1L1 mRNA expression at $2 \mathrm{~h}$ and $6 \mathrm{~h}$. We suggest that C3R may interact with NPC1L1 protein to inhibit the cholesterol uptake after a short exposure period [45]. In addition, the suppression of NPC1L1 mRNA expression by C3R appears to be the long-term mechanism for reducing cholesterol uptake into the enterocytes.

\section{Conclusions}

C3R inhibited pancreatic lipase and cholesterol esterase activity as well as cholesterol micellization. It also bound various types of bile acid (Fig. 6). In addition, C3R also inhibited cholesterol uptake in the enterocytes in both free cholesterol and mixed micelles. The inhibition may involve in the down-regulation of NPC1L1 mRNA expression. The findings suggest that C3R may be an effective compound, with promising anti-hyperlipidemic properties.

\section{Abbreviations \\ 4-MUO: 4-methylumbelliferyl oleate; C3G: Cyanidin-3-glucoside; \\ C3R: Cyanidin-3-rutinoside; GAPDH: Glyceroldehyde-3-phosphate \\ dehydrogenase; $I \mathrm{C}_{50}$ : The half maximal inhibitory concentration; NBD- cholesterol: 22-(N-(7-nitrobenz-2-oxa-1,3-diazol-4-yl)amino)-23,24-bisnor-5- cholen-3-ol; NPC1L1: Niemann-Pick C1-Like 1; p-NPB: p-nitrophenylbutylrate; RT-PCR: Real time-polymerase chain reaction}

\section{Acknowledgments}

Dr. Thavaree Thilavech wishes to thank Rachadapisek Sompote Fund for Postdoctoral Fellowship, Chulalongkorn University.

\section{Authors' contributions}

TT was responsible for the study concept and design, acquisition, analysis and interpretation of data, drafting the manuscript. SA contributed a concept of writing, the experimental design, data analysis and helped to draft the manuscript. Both authors read and approved the final manuscript.

\section{Funding}

This research was supported by Grant for International Research Integration: Chula Research Scholar, and Grant for Join Funding, Ratchadaphiseksomphot Endowment Fund, Chulalongkorn University. These funding sources supported the consumable materials, data collection, analysis, interpretation and preparation/writing of the manuscript/grammatical editing process fee.

\section{Availability of data and materials}

The datasets used and/or analysed during the current study available from the corresponding author Dr. Sirichai Adisakwattana (sirichai.a@chula.ac.th) on reasonable request.

Ethics approval and consent to participate

Not applicable.

\section{Consent for publication}

Not applicable.

\section{Competing interests}

The authors declare that they have no competing interests.

\section{Author details}

'Phytochemical and Functional Food Research Unit for Clinical Nutrition, Department of Nutrition and Dietetics, Faculty of Allied Health Sciences, Chulalongkorn University, Bangkok 10330, Thailand. ${ }^{2}$ Department of Food Chemistry, Faculty of Pharmacy, Mahidol University, Bangkok 10400, Thailand.

Received: 8 June 2018 Accepted: 30 August 2019

Published online: 05 September 2019

References

1. Kim SH, Song YH, Park S, Park MJ. Impact of lifestyle factors on trends in lipid profiles among Korean adolescents: the Korea National Health and nutrition examination surveys study, 1998 and 2010. Korean J Pediatr. 2016; 59(2):65-73

2. Karr S. Epidemiology and management of hyperlipidemia. Am J Manag Care. 2017:23(Suppl 9):S139-48.

3. Benjamin EJ, Blaha MJ, Chiuve SE, Cushman M, Das SR, Deo R, et al. Heart disease and stroke statistics-2017 dpdate: a report from the American Heart Association. Circulation. 2017;135(10):e146-603.

4. Tucci SA, Boyland EJ, Halford JC. The role of lipid and carbohydrate digestive enzyme inhibitors in the management of obesity: a review of 
current and emerging therapeutic agents. Diabetes Metab Syndr Obes. 2010;3:125-43.

5. Ros E. Intestinal absorption of triglyceride and cholesterol. Dietary and pharmacological inhibition to reduce cardiovascular risk. Atherosclerosis. 2000;151(2):357-9.

6. Cannon CP, Blazing MA, Giugliano RP, McCagg A, White J, Theroux P, et al. Ezetimibe added to statin therapy after acute coronary syndromes. N Engl J Med. 2015;372:2387-97.

7. Nussbaumer B, Glechner A, Kaminski-Hartenthaler A, Mahlknecht P, Gartlehner G. Ezetimibe-statin combination therapy. Dtsch Arztebl Int. 2016; 113(26):445-53.

8. Rossebo AB, Pedersen TR, Boman K, Brudi P, Chambers JB, Egstrup K, et al. Intensive lipid lowering with simvastatin and ezetimibe in aortic stenosis. N Engl J Med. 2008;359(13):1343-56.

9. Saghir SAM, Revadigar V, Murugaiyah V. Natural lipid-lowering agents and their effects: an update. Eur Food Res Technol. 2014;238(5):705-25.

10. Bahmani M, Mirhoseini M, Shirzad H, Sedighi M, Shahinfard N, RafieianKopaei $\mathrm{M}$. A review on promising natural agents effective on hyperlipidemia. J Evid Based Complement Altern Med. 2015;20(3):228-38.

11. Cicero AF, Colletti A. Role of phytochemicals in the management of metabolic syndrome. Phytomedicine. 2016;23(11):1134-44.

12. Pratheeshkumar $\mathrm{P}$, Son $\mathrm{YO}$, Korangath $\mathrm{P}$, Manu KA, Siveen KS. Phytochemicals in cancer prevention and therapy. Biomed Res Int. 2015; 2015:324021.

13. Nijveldt RJ, van Nood E, van Hoorn DE, Boelens $P G$, van Norren $K$, van Leeuwen PA. Flavonoids: a review of probable mechanisms of action and potential applications. Am J Clin Nutr. 2001;74(4):418-25.

14. Liu C, Sun J, Lu Y, Bo Y. Effects of anthocyanin on serum lipids in dyslipidemia patients: a systematic review and meta-analysis. PLoS One. 2016;11(9):e0162089.

15. Chen PN, Chu SC, Chiou HL, Kuo WH, Chiang CL, Hsieh YS. Mulberry anthocyanins, cyanidin 3-rutinoside and cyanidin 3-glucoside, exhibited an inhibitory effect on the migration and invasion of human lung cancer cell line. Cancer Lett. 2006;235(2):248-59.

16. Jung $H$, Kwank HK, Hwang KT. Antioxidant and antiinflammatory activities of cyanidin-3-glucoside and cyanidin-3-rutinoside in hydrogen peroxide and lipopolysaccharide-treated RAW264.7 cells. Food Sci Biotechnol. 2014;23(6): 2053-62.

17. Adisakwattana S, Yibchok-Anun S, Charoenlertkul P, Wongsasiripat N. Cyanidin-3-rutinoside alleviates postprandial hyperglycemia and its synergism with acarbose by inhibition of intestinal alpha-glucosidase. J Clin Biochem Nutr. 2011;49(1):36-41.

18. Akkarachiyasit S, Charoenlertkul P, Yibchok-Anun S, Adisakwattana S. Inhibitory activities of cyanidin and its glycosides and synergistic effect with acarbose against intestinal alpha-glucosidase and pancreatic alpha-amylase. Int J Mol Sci. 2010;11(9):3387-96.

19. Alzaid F, Cheung HM, Preedy VR, Sharp PA. Regulation of glucose transporter expression in human intestinal Caco-2 cells following exposure to an anthocyanin-rich berry extract. PLoS One. 2013;8(11):e78932.

20. Choi KH, Lee HA, Park MH, Han JS. Cyanidin-3-rutinoside increases glucose uptake by activating the PI3K/Akt pathway in 3T3-L1 adipocytes. Environ Toxicol Pharmacol. 2017;54:1-6.

21. Thilavech T, Ngamukote S, Abeywardena M, Adisakwattana S. Protective effects of cyanidin-3-rutinoside against monosaccharides-induced protein glycation and oxidation. Int J Biol Macromol. 2015;75:515-20.

22. Thilavech T, Ngamukote S, Belobrajdic D, Abeywardena M, Adisakwattana S. Cyanidin-3-rutinoside attenuates methylglyoxal-induced protein glycation and DNA damage via carbonyl trapping ability and scavenging reactive oxygen species. BMC Complement Altern Med. 2016;16(1):138.

23. Thilavech T, Abeywardena MY, Adams M, Dallimore J, Adisakwattana S. Naturally occurring anthocyanin cyanidin-3-rutinoside possesses inherent vasorelaxant actions and prevents methylglyoxal-induced vascular dysfunction in rat aorta and mesenteric arterial bed. Biomed Pharmacother. 2017:95:1251-9.

24. Elhabiri M, Figueiredo P, Fougerousse A, Brouillard R. A convenient method for conversion of flavonols into anthocyanins. Tetrahedron Lett. 1995;36(26): $4611-4$.

25. Makynen K, Jitsaardkul S, Tachasamran P, Sakai N, Puranachoti S, Nirojsinlapachai $\mathrm{N}$, et al. Cultivar variations in antioxidant and antihyperlipidemic properties of pomelo pulp (Citrus grandis [L.] Osbeck) in Thailand. Food Chem. 2013;139(1-4):735-43.
26. Reboul E, Soayfane Z, Goncalves A, Cantiello M, Bott R, Nauze M, et al. Respective contributions of intestinal Niemann-pick C1-like 1 and scavenger receptor class B type I to cholesterol and tocopherol uptake: in vivo v. in vitro studies. Br J Nutr. 2012;107(9):1296-304.

27. Feng D, Ohlsson L, Duan RD. Curcumin inhibits cholesterol uptake in Caco2 cells by down-regulation of NPC1L1 expression. Lipids Health Dis. 2010; 9(1):40.

28. Kianbakht S, Abasi B, Hashem Dabaghian F. Improved lipid profile in hyperlipidemic patients taking Vaccinium arctostaphylos fruit hydroalcoholic extract: a randomized double-blind placebo-controlled clinical trial. Phytother Res. 2014;28(3):432-6.

29. Zhu Y, Ling W, Guo H, Song F, Ye Q, Zou T, et al. Anti-inflammatory effect of purified dietary anthocyanin in adults with hypercholesterolemia: a randomized controlled trial. Nutr Metab Cardiovasc Dis. 2013;23(9):843-9.

30. Wu T, Qi X, Liu Y, Guo J, Zhu R, Chen W, et al. Dietary supplementation with purified mulberny (Morus australis Poir) anthocyanins suppresses body weight gain in high-fat diet fed C57BL/6 mice. Food Chem. 2013;141 (1):482-7.

31. Yao SL, Xu Y, Zhang YY, Lu YH. Black rice and anthocyanins induce inhibition of cholesterol absorption in vitro. Food Funct. 2013;4(11):1602-8.

32. Fabroni S, Ballistreri G, Amenta M, Romeo FV, Rapisarda P. Screening of the anthocyanin profile and in vitro pancreatic lipase inhibition by anthocyanincontaining extracts of fruits, vegetables, legumes and cereals. J Sci Food Agric. 2016;96(14):4713-23.

33. McKinney JD, Richard A, Waller C, Newman MC, Gerberick F. The practice of structure activity relationships (SAR) in toxicology. Toxicol Sci. 2000;56(1):8-17.

34. You Q, Chen F, Wang X, Luo PG, Jiang Y. Inhibitory effects of muscadine anthocyanins on alpha-glucosidase and pancreatic lipase activities. J Agric Food Chem. 2011;59(17):9506-11.

35. Olivas-Aguirre FJ, Rodrigo-Garcia J, Martinez-Ruiz ND, Cardenas-Robles Al, Mendoza-Diaz SO, Alvarez-Parrilla E, et al. Cyanidin-3-O-glucoside: physicalchemistry, Foodomics and health effects. Molecules. 2016;21(9):1264.

36. He H, Lu YH. Comparison of inhibitory activities and mechanisms of five mulberry plant bioactive components against alpha-glucosidase. J Agric Food Chem. 2013;61(34):8110-9.

37. Iqbal J, Hussain MM. Intestinal lipid absorption. Am J Physiol Endocrinol Metab. 2009;296(6):E1183-94

38. Heidrich JE, Contos LM, Hunsaker LA, Deck LM, Vander Jagt DL. Inhibition of pancreatic cholesterol esterase reduces cholesterol absorption in the hamster. BMC Pharmacol. 2004;4(1):5.

39. Gururaja GM, Mundkinajeddu D, Dethe SM, Sangli GK, Abhilash K, Agarwal A. Cholesterol esterase inhibitory activity of bioactives from leaves of mangifera indica I. Pharm Res. 2014;7:355-62.

40. Kumar TS, Aishwarya M, Archana K, Divya S, Lakshmi SS. Impact of polyphenols on cholesterol esterase inhibition-a mini review. Int Res J Eng Tech. 2016;3(10):1058-62.

41. Hui DY, Howles PN. Molecular mechanisms of cholesterol absorption and transport in the intestine. Semin Cell Dev Biol. 2005;16(2):183-92.

42. Vermeer MA, Mulder TP, Molhuizen HO. Theaflavins from black tea, especially theaflavin-3-gallate, reduce the incorporation of cholesterol into mixed micelles. J Agric Food Chem. 2008:56(24):12031-6.

43. Insull W Jr. Clinical utility of bile acid sequestrants in the treatment of dyslipidemia: a scientific review. South Med J. 2006;99(3):257-73.

44. Artursson P, Karlsson J, Ocklind G, Schipper N. Studying transport processes in absorptive epithelia. In: Shaw AJ, editor. Epithelial cell culture: a practical approach. New York: Oxford Press; 1996. p. 111-33.

45. Jia L, Betters JL, Yu L. Niemann-pick C1-like 1 (NPC1L1) protein in intestinal and hepatic cholesterol transport. Annu Rev Physiol. 2011;73:239-59.

\section{Publisher's Note}

Springer Nature remains neutral with regard to jurisdictional claims in published maps and institutional affiliations. 